\title{
Evidence for emotionally-induced coronary arterial spasm in patients with angina pectoris ${ }^{\star}$
}

\author{
FREDRIC SCHIFFER, L HOWARD HARTLEY, CHARLES L SCHULMAN, \\ WALTER H ABELMANN
}

From the Department of Medicine and Thorndike Laboratory, Harvard Medical School and
Beth Israel Hospital, Boston, Mass, USA

SUMmaRY Twelve executives with typical angina pectoris, given a 12-minute quiz, designed to be psychologically stressful, responded with ST depressions of $\geqslant 1.0 \mathrm{~mm}$. Each of these patients was given an exercise tolerance test on an upright bicycle to induce an amount of ST depression equivalent to that observed during the quiz. A statistical analysis was made of the products of the heart rate and the systolic blood pressure (rate-pressure product), at the onset of equivalent ST depression on both tests. At the maximal ST depression during the quiz, the mean rate-pressure product was $181 \pm 64(\mathrm{SD}) \times 10^{2}$, and at an equivalent ST depression during exercise it was $225 \pm 54 \times 10^{2}$; the mean difference was $44 \pm 40 \times 10^{2}$.

Inasmuch as the rate-pressure product is an index of myocardial oxygen consumption, the differences in rate-pressure product suggest that myocardial ischaemia occurred at a lower myocardial oxygen consumption during emotional stress than during exercise. If equivalent degrees of ST depression during exercise and the quiz are indicative of equivalent ischaemia, then a relative reduction in coronary blood flow during emotional stress, probably by coronary spasm, may be postulated as the most reasonable explanation for these observations.

It has been observed that, in patients with angina pectoris, chest pain tends to be produced whenever the myocardial oxygen consumption exceeds a critical value. ${ }^{1}$ Whether the angina occurred spontaneously or in response to exercise, it seemed always to recur at about the same myocardial oxygen consumption for each patient. These results furthered the theory that angina was produced by a fixed atherosclerotic coronary lesion and seemed to refute a role for coronary spasm in the syndrome of typical angina pectoris. Robinson ${ }^{1}$ reported one $^{2}$ patient who developed angina in response to performing mental arithmetic as well as to exercise. Using the rate-pressure product (heart rate multiplied by systolic blood pressure) as an index of myocardial oxygen consumption, he noted that the rate-pressure products were similar at the onset of the angina, regardless of how it was provoked. He

\footnotetext{
* This research was supported, in part, by grants from the National Heart and Lung Institute, and by a grant from the General Clinical Research Centers Program of the Division of Research Resources, National Data Organization, and analysis was performed on the PROPHET System, a national computer resource sponsored by the Chemical/Biological Information Handling Program, National Institutes of Health.

Received for publication 5 November 1979
}

suggested that emotional stress, like exercise, provokes angina by increasing the myocardial oxygen consumption above a critical level.

We examined the relation between angina pectoris and emotional stress using a larger patient population and electrocardiographic criteria for myocardial ischaemia, rather than subjective patient reporting. A comparison was made of the rate-pressure products at the time of equivalent ST responses to exercise and to emotional stress.

\section{Subjects and methods}

Thirty-six patients with angina pectoris and not taking digitalis were given a 12-minute tape recorded quiz, designed to be stressful, while the electrocardiogram and blood pressure were being monitored. A full description of the quiz electrocardiogram has been reported. ${ }^{2}$ Those patients manifesting at least $1 \mathrm{~mm}$ of ST segment depression in response to the quiz were selected for exercise tolerance testing.

Each patient, upon arrival at the cardiovascular laboratory, was familiarised with the laboratory and 
then asked for written informed consent to the study. The tests were given without cost or remuneration to the patient. After a detailed history and physical examination, a 12 lead, supine, resting electrocardiogram was recorded. A brief unstructured psychiatric interview was also conducted. No patient was accepted for study who manifested unstable angina, recent myocardial infarction (within six weeks), unstable resting electrocardiogram, or other significant illness except stable hypertension. All tests were performed in an exercise laboratory, using the same precautions as are used for tolerance testing. ${ }^{3}$ For both the quiz electrocardiogram and the exercise tolerance test, exercise electrocardiographic electrodes were applied as described by Mason and Likar. ${ }^{4}$ The electrocardiogram was calibrated to $1 \mathrm{mV} / 10 \mathrm{~mm}$, and the response signal was evaluated before each test. Blood pressure measurements were obtained by auscultation using a standard sphygmomanometer. Diastolic blood pressure was determined by the disappearance of the Korotkoff sounds.

A baseline electrocardiogram was recorded with the exercise electrodes, with the patient sitting in the same position used during exercise and the quiz. Three baseline blood pressure readings were also taken.

Subjects were then instructed to answer questions asked on a 12-minute tape recording. ${ }^{2}$ During this quiz, the electrocardiogram was monitored continuously, and the blood pressure was measured at least every two minutes.

The 12 patients with positive responses to the quiz electrocardiogram constituted the study group. They were given an upright bicycle exercise tolerance test to induce an equivalent ST segment depression. Progressively more intense four-minute work loads, each followed by a five-minute rest period, were used. Blood pressure was measured by auscultation during the last minute of each exercise load, or at the onset of ST segment depression.

Most of the exercise tests were performed on the same day as the quiz electrocardiogram, with a 45-minute rest period between tests. When the tests were performed on different days, they were performed within 48 hours of each other. Both the quiz electrocardiogram and the exercise tolerance test used the same monitoring leads, and were conducted at a room temperature of $21^{\circ} \mathrm{C}\left(70^{\circ} \mathrm{F}\right)$ and at approximately the same time of day with patients in the fasting state and in the same body position.

Using the criteria of Ellestad and Wan, ${ }^{5}$ the ST segments were carefully measured with a magnifying glass, using the $P Q$ junction as a reference. The ST segment depression at 0.08 second after the
J point was considered as the extent of depression. Each reported ST segment value represented the average of the measurements of 10 consecutive beats.

All the patients in this study were executives, defined as those whose occupation is classified by the US Bureau of the Census as either professional, managerial, or sales. ${ }^{6}$ A previous study has shown that executives tend to respond significantly more to the quiz electrocardiogram than do nonexecutives. ${ }^{2}$

The study group consisted of 11 men and one woman, aged 52 to 69 years (mean 62). All had typical angina, defined as recurrent chest pressure discomfort of brief duration, usually precipitated by physical exertion. Two had undergone coronary angiography, each revealing at least 70 per cent occlusion of a coronary artery; five had a history of a documented myocardial infarction; and two had a history of hypertension. One patient was taking propranolol at the time of the study; otherwise no medication known to affect the cardiovascular system was taken for 72 hours before the study. The 12 patients in the study group did not differ from the 24 patients who had less than $1.0 \mathrm{~mm} \mathrm{ST}$ depression on the questionnaire, with regard to physical examination, history, or psychiatric interview.

\section{Results}

ST SEGMENT RESPONSES

In each of the 12 patients who developed $\geqslant 1.0 \mathrm{~mm}$ ST segment depression during the quiz electrocardiogram, exercise testing was able to induce an amount of ST segment depression equivalent to that on the quiz. The Figure shows the equivalent ST segment changes for four patients. No patient developed chest pain during the study.

\section{DIFFERENCES IN THE RATE-PRESSURE PRODUCTS}

The Table presents the individual heart rates, blood pressures, and rate-pressure products for both tests at the onset of ST segment depression. A statistical analysis was made of the rate-pressure products at the time of equivalent ST segment depressions on both tests. At the time of maximal ST depression during the quiz, the mean ratepressure product was $181 \pm 64(\mathrm{SD}) \times 10^{2}$, and at an equivalent $S T$ depression during exercise it was $225 \pm 54$ (SD) $\times 10^{2}$. The mean difference was $44 \pm 40(S D) \times 10^{2}$. By paired t test $p$ was $<0.005$.

\section{Discussion}

Roughgarden ${ }^{7}$ reported that patients with spon- 


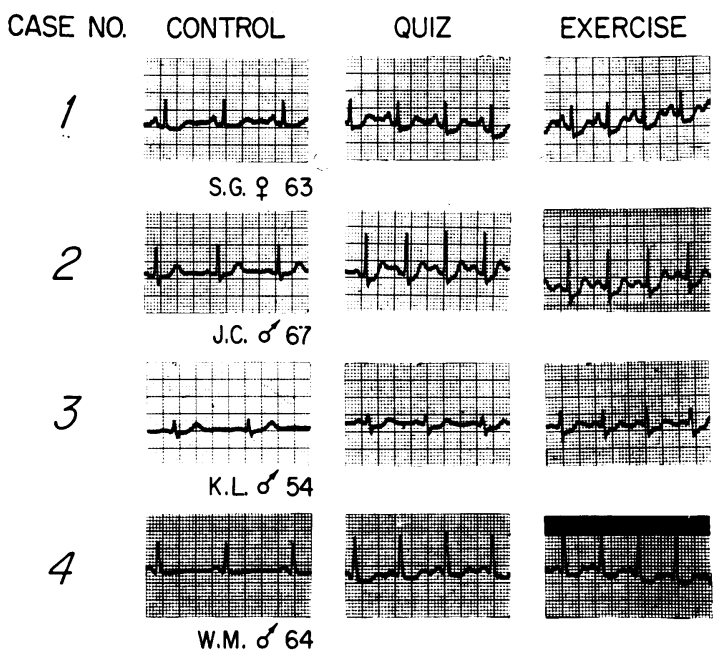

Fig. The control electrocardiograms before the quiz and the equivalent electrocardiographic response to the quiz and to exercise of four patients with typical angina pectoris. None of these patients had undergone angiography, and none was taking drugs at the time of study. All tracings were recorded from lead V5 with the exception of those of case 1 which were recorded from lead II.

taneous angina had symptoms that were preceded by increases in heart rate and blood pressure. Similarly, Robinson ${ }^{1}$ showed that 15 patients with angina pectoris, who exercised on two or more occasions, had angina which tended to occur when a critical rate-pressure product was exceeded. He also reported one patient who developed angina in response to the emotional stress of performing mental arithmetic, as well as to an exercise stress. In that patient, angina occurred when a critical ratepressure product was exceeded, regardless of the type of provocative stress. The work of Roughgarden $^{7}$ and Robinson ${ }^{1}$ thus tends to argue against a significant role for coronary spasm in ischaemic heart disease.

Using the same basic arguments as Robinson, ${ }^{1}$ we hypothesised that if ischaemia were the result of a fixed coronary blockage, then the myocardial oxygen consumption at the onset of ischaemia should be the same regardless of how the ischaemia was provoked. In 12 patients we were able to provoke ST segment responses suggesting ischaemia under two conditions: emotional stress and physical stress. Ischaemic ST responses occurred at significantly lower rate-pressure products during emotional stress than during exercise stress. If ST depression during exercise had occurred when a "critical" rate-pressure product was reached, then during the emotional stress the ST depression occurred at a point significantly below the alleged "critical" rate-pressure product.

The rate-pressure product is considered to be a valid index of myocardial oxygen consumption. ${ }^{8-10}$ The occurrence of ST segment depression at a lower rate-pressure product reflects less coronary blood flow only if the myocardial oxygen demands are faithfully reflected in the rate-pressure product. Increased left ventricular volume leads to increased wall tension, and thus myocardial oxygen uptake is increased for any given rate-pressure product. ${ }^{11}$ Hence, if ventricular volume were greater for the psychological stress than during exercise, more ST segment depression would be expected. In this

Table Individual heart rates, blood pressures, and rate-pressure products at time of equivalent $S T$ responses to quiz and to exercise

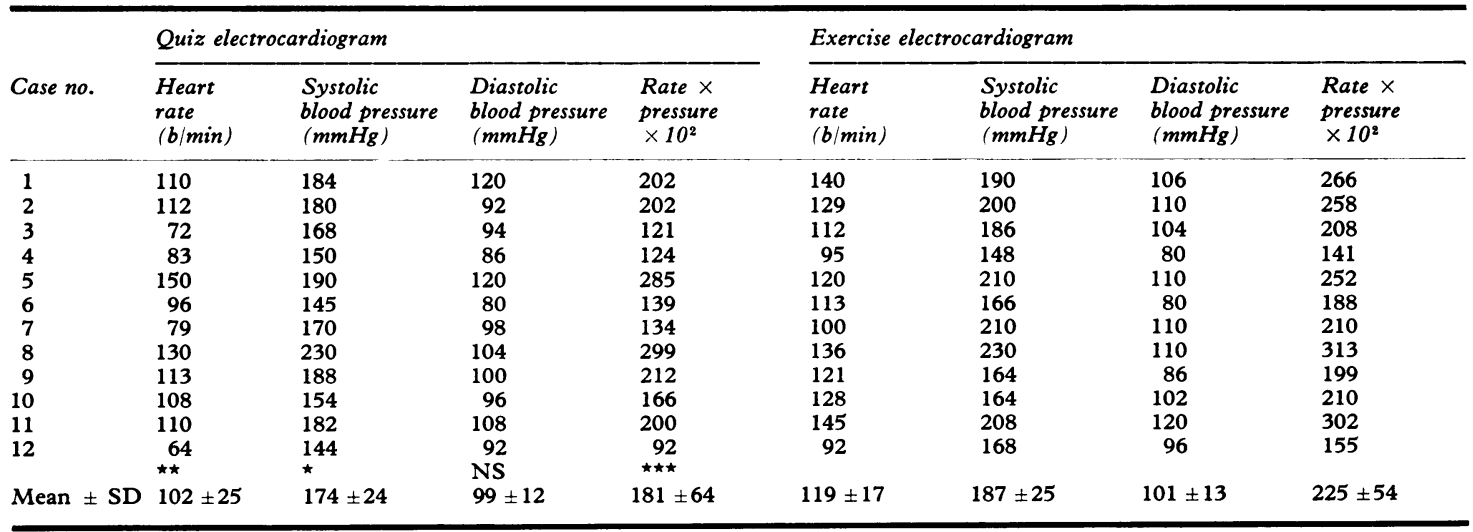

$\star p \leqslant 0.02$ (compared with exercise); $\star \star p \leqslant 0.01$ (compared with exercise); ${ }^{\star} \star \star p \leqslant 0.005$ (compared with exercise);

NS, not significant; SD, standard deviation. 
study, at the time of the equivalent ST depression, the systolic pressure was slightly but significantly lower during the emotional quiz compared to exercise. This lower pressure would be expected to be associated with a lesser ventricular volume. Also, during exercise, the increased venous return would be expected to lead to a larger ventricular volume than during emotional stress. ${ }^{12} 13$ On the other hand, emotional stress may be associated with increased venous tone ${ }^{14}$ which might lead to an increase in central venous pressure and ventricular volume. Therefore, alterations of ventricular volume have not been ruled out. Myocardial contractility may also affect myocardial oxygen demands $^{15}$ and, in view of the higher heart rate during exercise, may have been higher during exercise stress.

We compared the rate-pressure products at equivalent amounts of ST segment depression during the exercise and emotional stress. Though it cannot be considered proven that equivalent amounts of ST segment depression represent equivalent amounts of ischaemia, this assertion is supported by work in animals. ${ }^{16}{ }^{17}$ ST segment depression is a more objective index of the degree of myocardial ischaemia than subjective reporting of a chest discomfort.

If the rate-pressure product adequately reflects the myocardial oxygen consumption, and if equivalent amounts of ST segment depression represent equivalent amounts of ischaemia, then the most likely explanation for our findings is that emotional stress provoked a transient, relative decrease in myocardial oxygen delivery. A hypothesis that a shift in the oxyhaemoglobin curve could produce clinical ischaemia has not been sustained. ${ }^{18}$ A hypothesis that platelet aggregation might cause a transient coronary obstruction has some support from work on a dog preparation, ${ }^{19}$ but has not yet been demonstrated to have clinical significance in angina patients. Generalised or local constrictionor even local dilatation-of coronary resistance vessels are potential but unproven pathophysiological mechanisms by which emotion might induce ischaemia. Furthermore, ST and $T$ changes resembling myocardial ischaemia have been encountered at rest in healthy men with normal coronary arteriograms and attributed to catecholamine hypersecretion or hypersensitivity. ${ }^{20}$ On the other hand, it is known that the conducting coronary arteries contain smooth muscle which is sensitive to neural and chemical stimulation and which has been repeatedly shown by coronary visualisation to cause clinically significant coronary spasm. ${ }^{21-23}$

Our observations in patients with classical angina are compatible with the hypothesis that coronary artery spasm, in addition to atherosclerosis, may play a role in the production of the ischaemic electrocardiographic responses to emotional stress.

\section{References}

${ }^{1}$ Robinson BF. Relation of heart rate and systolic blood pressure to the onset of pain in angina pectoris. Circulation 1967; 35: 1073-83.

${ }^{2}$ Schiffer F, Hartley LH, Schulman CL, Abelmann WH. The quiz electrocardiogram: a new diagnostic and research technique for evaluating the relation between emotional stress and ischemic heart disease. $\mathrm{Am} \mathrm{f}$ Cardiol 1976; 37: 41-7.

${ }^{3}$ Bruce RA, Irvine JB. Exercise electrocardiography. In: Hurst JW, ed. The heart, arteries and veins. New York: McGraw-Hill, 1978: 336.

${ }^{4}$ Mason RE, Likar I. A new system of multiple-lead exercise electrocardiography. Am Heart $\mathcal{F} 1966$; 71: 196-205.

${ }^{5}$ Ellestad MH, Wan KC. Predictive implications of stress testing: follow-up of 2700 subjects after maximum treadmill stress testing. Circulation 1975; 51: 363-9.

${ }^{6}$ United States. Bureau of the Census. Occupation by Industry. Census of Population 1970. PC (2) -7C. Washington, DC: US Government Printing Office, 1973-4.

'Roughgarden JW. Circulatory changes associated with spontaneous angina pectoris. $A m \mathcal{F}$ Med 1966; 41: 947-61.

${ }^{8}$ Sarnoff SJ, Braunwald E, Welch GH Jr, Case RB, Stainsby WN, Macruz R. Hemodynamic determinants of oxygen consumption of the heart with special reference to the tension-time index. Am $\mathcal{F}$ Physiol 1958; 192: 148-56.

${ }^{9} \mathrm{Kitamura} \mathrm{K}$, Jorgensen CR, Gobel FL, Taylor HL, Wang Y. Hemodynamic correlates of myocardial oxygen consumption during upright exercise. $\mathrm{f} A \mathrm{Apl}$ Physiol 1972; 32: 516-22.

${ }^{10}$ Gobel FL, Norstrom LA, Nelson RR, Jorgensen CR, Wang $Y$. The rate-pressure product as an index of myocardial oxygen consumption during exercise in patients with angina pectoris. Circulation 1978; 57: 549-56.

${ }^{11}$ Monroe RG, French GN. Left ventricular pressurevolume relationships and myocardial oxygen consumption in the isolated heart. Circ Res 1961; 9: 362-74.

${ }^{12}$ Lichtlen $P$. The hemodynamics of clinical ischemic heart disease. Ann Clin Res 1971; 3: 333-43.

${ }^{13}$ Borer JS, Bacharach SL, Green MV, Kent KM, Epstein SE, Johnston GS. Real-time radionuclide cineangiography in the non-invasive evaluation of global and regional left ventricular function at rest and during exercise in patient with coronary artery disease. $N$ Engl f Med 1977; 296: 839-44.

${ }^{14}$ Duggan JJ, Love VL, Lyons RH. A study of reflex venomotor reactions in man. Circulation 1953; 7: 869-75.

${ }^{15}$ Sonnenblick EH, Morrow AG, Williams JF Jr. Effects 
of heart rate on the dynamics of force development in the intact human ventricle. Circulation 1966; 33: 945-51.

${ }^{16}$ Ekmekci A, Toyoshima H, Kowczynski JK, Nagaya T, Prinzmetal M. Angina pectoris IV: clinical and experimental differences between ischemia with ST elevation and ischemia with ST depression. $A m \mathcal{F}$ Cardiol 1975; 51 : 363-9.

${ }^{17}$ Case RB, Roselle HA, Crangster RS. Relation of ST depression to metabolic and hemodynamic events. Cardiologia 1966; 48: 32-41.

${ }^{18}$ Vokonas PS, Cohn PF, Klein MD, Laver MB, Gorlin R. Hemoglobin affinity for oxygen in the anginal syndrome with normal coronary arteriograms (abstract). Am f Cardiol 1970; 26: 664-5.

${ }^{19}$ Folts JD, Crowell EB Jr, Rowe GG. Platelet aggregation in partially obstructed vessels and its elimination with aspirin. Circulation 1976; 54: 365-70.

${ }^{20}$ Taggart $\mathrm{P}$, Carruthers M, Joseph S, et al. Electro- cardiographic changes resembling myocardial ischaemia in asymptomatic men with normal coronary arteriograms. Br Heart $\mathcal{F}$ 1979; 41: 214-25.

${ }^{21}$ Dhurandhar RW, Watt DL, Silver MD, Trimble AS, Adelman AG. Prinzmetal's variant form of angina with arteriographic evidence of coronary arterial spasm. Am f Cardiol 1972; 30: 902-5.

${ }^{22}$ Kerin N, Macleod CA. Coronary artery spasm associated with variant angina pectoris. $B r$ Heart $\mathcal{F} 1974$; 36: 224-7.

${ }^{23}$ Chahine TA, Raizner AE, Ishimori T, Luchi RJ, McIntosh HD. The incidence and clinical implications of coronary artery spasm. Circulation 1975; 52: 972-8.

Requests for reprints to $\mathrm{Dr}$ Walter H Abelmann, Cardiovascular Unit, Beth Israel Hospital, 330 Brookline Avenue, Boston, Massachusetts 02215, USA. 